\title{
The Influence of Air Fuel Ratio on the Performances and Emissions of a SINJAI-150 Bioethanol Fueled Engines
}

\author{
Ari Kurniawan Saputra ${ }^{1}$, Bambang Sudarmanta周, Ibnu Irawan ${ }^{1}$, Atok Setiyawan ${ }^{1}$, Alief \\ Wikarta $^{1}$, I. Nyoman Sutantra ${ }^{1}$, Dori Yuvenda ${ }^{2}$ \\ ${ }^{1}$ Department of Mechanical Engineering, ITS, Sukolilo, Surabaya 60111, Indonesia \\ ${ }^{2}$ Department of Automotive Engineering, Universitas Negeri Padang, Padang 25171, Indonesia \\ Received: September 2018, Revised: September 2018, Accepted: September 2018
}

\begin{abstract}
In the present work the effect of variation of air fuel ratio on performances and emissions SINJAI-150 engine with bioethanol were conducted. Variation of air fuel ratio is done by setting the mass flow rate of combustion air using supercharger. Engine performance was measured using water brake dynamometer with variable speed standard from 2000 to $8000 \mathrm{rpm}$ at full open throttle condition. The results indicate that the natural intake system produces relatively rich air fuel ratio, with an average lambda of 0.68 , so that resulting performance is not maximum. The addition of aspirated 1 and 2 combustion air with the results in the form of average lambda at intervals of $0.8-1.1$. On the aspirated 2 , thermal efficiency increase averaged $50.32 \%$, specific fuel consumption decrease averaged $32.74 \%$, and $\mathrm{CO}$ and $\mathrm{HC}$ emissions reduction average of $7.43 \%$ and $25.77 \%$.
\end{abstract}

Keyword : SINJAI-150 engine, Performances, Bioethanol, Emissions, Air fuel ratio, Lambda

\section{Introduction}

In Indonesia, current issues of energy sector can be summarized as depletion of fossil energy reserves, limited access to energy especially in remote and border areas and degradation of the global environment. The use of oil fuels (gasoline, diesel oil, fuel oil, kerosene and avtur) still dominate the national energy demand with $31.5 \%$ share in 2014 and will increase up to $40.7 \%$ and $42.5 \%$ in base scenario and high scenario respectively by 2050. This happens because the oil fuel-based technology is more efficient than others, especially in transport sector[1].

The transportation sector is the biggest contributor to the degradation of the global environment which produces $73 \%$ of $\mathrm{CO} 2$ gas from 600 million vehicles that operate every day, and the rest from the industrial and household sectors [1]. The increasing need for fossil fuels is not comparable to its ever-decreasing availability, both in the form of potential and proven reserves. The world's fossil oil reserves will meet the world's energy needs of less than 80 years, while for the ASEAN region and Indonesia the availability of fossil energy only lasts approximately 20 and 12 years. Based on these problems, new renewable and environmentally friendly energy has the potential to be developed.

Based on its availability and properties, bioethanol is one of the alternative fuels in the internal combustion engine [2] [3]. In normal combustion the air and fuel mixture will burn perfectly when it is in a stoichiometric mixture. For C8H18 gasoline fuel, the stoichiometric air requirement is 14.7 while for bioethanol fuel, $\mathrm{C} 2 \mathrm{H} 5 \mathrm{OH}$ needs stoichiometric air 9. However, the energy content is low compared to gasoline $(65 \%)$ [4] and higher of heat of vaporization (300\%) [5] so that in its use to produce the same power consumption is required greater fuel. In its application, it is carried out by increasing the injection volume or enlarging the fuel spray hole[6] [7]. Paloboran et al [8] conducted an ignition timing mapping and injection duration of $100 \%$ bioethanol fuel with natural air intake indicating that the resulting lambda value was below 0.8 . This indicates that the mixture is relatively rich so that it has the potential to produce incomplete carbon emissions, such as $\mathrm{HC}$ and $\mathrm{CO}$.

Based on the description above, we want to add combustion air using a supercharger which is varied by the voltage of the driving motor to increase the mixed lambda value so that it can produce a more perfect combustion.

\section{Experimental Setup and Procedures}

In this study, the experiments were performed by SINJAI-150 bioethanol fueled engines, $16 \mathrm{hp}$, one cylinder, and spark plug ignition system. The engine specifications is given in Table 1 .

\footnotetext{
*Email: sudarmanta@me.its.ac.id, phone: (+62) 8123067561
} 
Table 1. SINJAI-150 bioethanol-fueled engine specifications

\begin{tabular}{ll}
\hline Engine Type & SINJAI 150 \\
\hline Number of cylinder & 1 \\
Bore x stroke & 63.5 x 47 mm \\
Displacement volume & $150 \mathrm{cc}$ \\
Compression ratio & 12.5 \\
Control system & Programmable ECU \\
Fuel intake system & Port injection \\
Maximum torque & $30 \mathrm{Nm} / 3000 \mathrm{rpm}$ \\
Injecto & Heated bioethanol injector \\
Maximum power & $16 \mathrm{HP} / 4000 \mathrm{rpm}$ \\
\hline Coolant system & Air \\
\hline
\end{tabular}

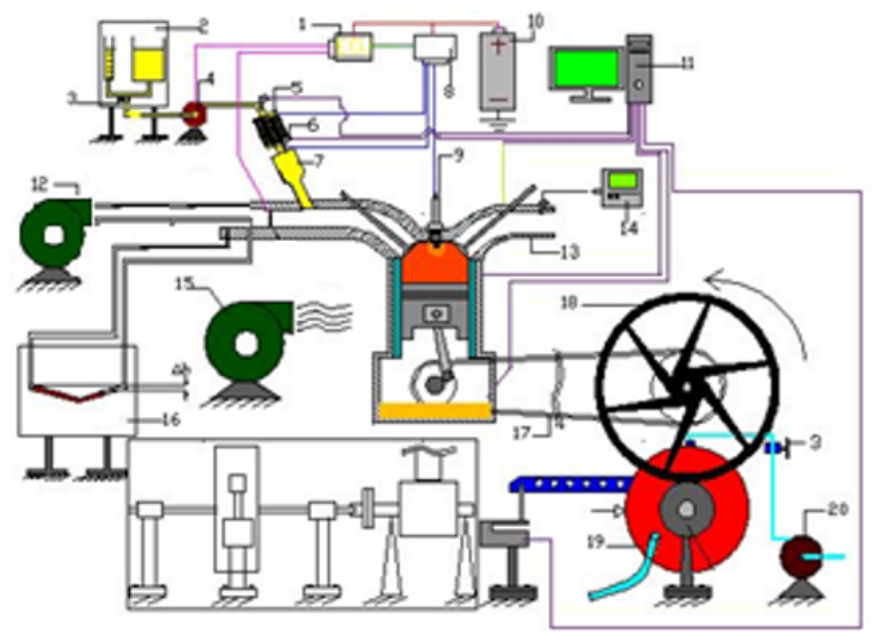

Caption:
1. Fuel tank
2. Measuring glass
3. Filter fuel
4. Port injection system
5. Cables trottle
6. SINJAI engine
7. Exhaust muffler
8. Coupling
9. Tachometer
10. Battery
11. Valve
12. Electric supercharger
13. Water reservoir
14. blower

Caption:

2. Measuring glass

3. Filter fuel

4. Port injection system

Cables trottle

7. Exhaust muffler

8. Coupling

9. Tachometer

10. Battery

12. Electric supercharger

14. blower
15. Cold Supercharger

16. Manometer V

17. Chain

18. Wheel

19. Water brake dyno

20. Water pump

Figure 1. Schematic diagram of the experimental setup

The injector used is a special injector for bioethanol fuel which is equipped with a heating system [8]. Waterbrake dynamometer with power capacity $20 \mathrm{HP}$ used in these experiments. The fuel consumption was measured by the time fuel consumption per $25 \mathrm{cc}$ of fuel in a measuring glass, whereas combustion air consumption was measured using an air flow meter. The emission parameters, exhaust gas temperature and air fuel ratio were measured using STARGAS exhaust gas analyzer. The fuel measuring glass was fitted to Sinjai-150 bioethanol fueled engines and it contained bioethanol fuel. A schematic diagram of experimental setup is shown in Fig. 1 .

This engine is equipped with a programmable electronic control unit that has the facility to adjust injection suitability and ignition timing. The ECU function is to control the fuel quantity, injection time, ignition time and engine speed by receiving signals from six sensors. These sensors are oxygen sensors, manifold air pressure sensors, inlet air temperature sensors, throttle position sensors, cooled water temperature sensors and engine speed sensors. The single port fuel injection system is used to inject fuel into the port entry valve area into the combustion chamber. The combustion air is inserted naturally (as a reference and then called naturally) and pressed using an electric supercharger. The mechanism of work of the electric supercharger is to set the switch on/off, where when switching on, the source of electricity flows from the alternator to the relay and generates magnetism in the relay which automatically turns on the relay switch, then the source of electricity from the battery flows to the drive motor (DC motor) and drive an electric supercharger to supply the combustion air in. Variations made by adjusting the voltage of the supercharger drive motor, starting at 8, 12 and 14 volts, which are then called aspirated 1, 2 and 3 respectively.

The ECU engine is employed to optimize fuel injection and ignition timing for the engine. In this variation of testing, setting a mixture of fuel and air has an equivalence ratio at intervals of 0.8 to 1.2. Optimization is aimed at minimizing the amount of fuel necessary to obtain the maximum torque [5] [6]. The ignition timing was set for minimum advance for best torque (MBT) or limited by knock which occurred first. The series of tests were carried out using bioethanol with natural combustion air and pressed with an electric supercharger with a voltage variation of 8, 10 and 12 volts respectively. All variations of the tests were tested with variable engine speed method. Measurement of test parameters is carried out after steady 
Table 2. The properties of fuels

\begin{tabular}{llll}
\hline Parameters & Unit & Gasoline & Bioethanol \\
\hline Chemical Formula & - & $\mathrm{C} 8 \mathrm{H} 18$ & $\mathrm{C} 2 \mathrm{H} 6 \mathrm{O}$ \\
C-fraction Mass & $\% 87.4$ & 52,2 & \\
H-fraction Mass & $\% 12.6 \% 13,0$ & & \\
O-fraction Mass & $\%$ O & 34,7 & \\
$\mathrm{H} / \mathrm{C}$ & Atom ratio & 1,795 & 3 \\
O/C & Atom ratio & 0 & 0,5 \\
Molar Weight & $\mathrm{kg} / \mathrm{kmol}$ & 114 & 46 \\
Research Octane Number & $\mathrm{RON}$ & 88 & 105 \\
Specific Gravity & - & 0.76 & 0.81 \\
Latent heat of vaporization & $\mathrm{kJ} / \mathrm{kg}$ & 289 & 854 \\
Lower Heating Value & $\mathrm{kJ} / \mathrm{kg}$ & 42690 & 26805 \\
Laminer Flame Speed at $1=1$ & $\mathrm{~cm} / \mathrm{s}$ & 41 & 56 \\
Stoichiometric AFR & - & 14.7 & 9 \\
Autoignition temperature & ${ }^{\circ} \mathrm{C}$ & 350 & 420 \\
Reid vapour pressure at $37,8{ }^{\circ} \mathrm{C}$ & $\mathrm{kPa}$ & $53-60$ & 17 \\
\hline Flash point & ${ }^{\circ} \mathrm{C}$ & -40 & 13 \\
Auto ignition temperature & ${ }^{\circ} \mathrm{C}$ & 257 & 425 \\
\hline
\end{tabular}

engine conditions. The engine speed, fuel consumption, water brake load engine, emission parameters such as $\mathrm{CO}$ and $\mathrm{HC}$ emissions and engine temperature were measured, while the brake of power, mean effective pressure, specific fuel consumption and thermal efficiency were computed. All experiments have been carried out at full open throttle settings.

The bioethanol fuels were prepared just before starting the experiment to ensure that the fuel ready and to avoid the reaction of bioethanol with water. Fuel properties are shown in Table 2

\section{Result and Discussion}

The results of the study were shown starting from the change in the value of air fuel ratio (AFR) and equivalent ratio (lambda) with the addition of electric super cherger, as shown in Fig. 2 and 3 .

Figure 2 shows that the trend of the AFR value along

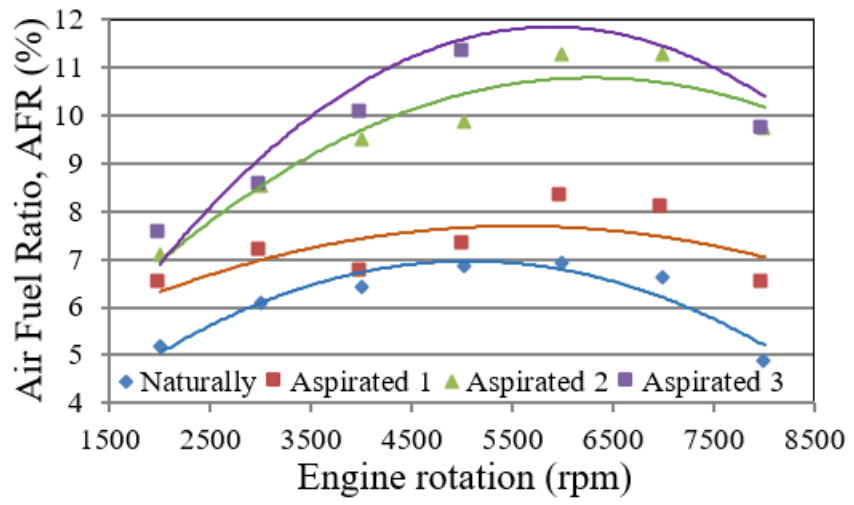

Figure 2. AFR function of engine rotation with the increase in engine speed is increased until it reaches the peak in the middle engine speed and tends to decrease with increasing engine rotation, where the stoichiometric AFR value of bioethanol is 9. This is due to the mechanism of testing the variable speed with the full open throttle system, adding the load causes the engine speed to decrease. In addition to load, from low to medium load, the addition of fuel is smaller than the decrease in combustion air intake so that the AFR tends to rise. In this condition the AFR value can exceed the stoichiometric value as shown in Fig. 2 or in other words the lambda value exceeds the value of one as shown in Fig. 3 whereas in the addition of loads to high loads, the addition of fuel is higher than the reduction in combustion air, so that the AFR value tends to decrease even though it tends to be above the stoichiometric value as shown in Fig. 2 or the lambda value is still above the one value as shown in Fig. 3 .

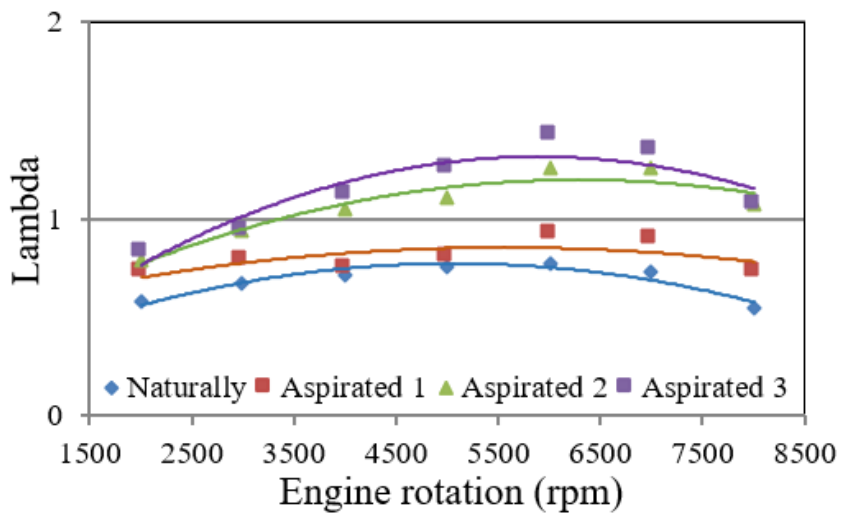

Figure 3. Lambda function of engine rotation 
Variations in the addition of combustion air through the adjustment of the voltage of the supercharger driving motor show an increase in the average value of AFR and lambda on aspirated 1 (voltage 8 volts) of $17.6 \%$, aspirated 2 (voltage 10 volts) of $56.4 \%$ and aspirated 3 (voltage 12 volts) of $67.4 \%$. If we look at Fig. 3, the lambda value for natural conditions and aspirated 1 is still below 1 , which is 0.68 and 0.80 , while in aspirated 2 and 3 the lambda value is above 1 , which is 1.07 and 1.14 . This means that the addition of a supercharger is intended to find out the effect of air and fuel mixtures on engine performance and emissions, where the air mixture varies from a mixture of rich to poor.

Engine performance is indicated by torque, BMEP, SFC power and thermal efficiency at 2000 to $8000 \mathrm{rpm}$. Torque is a measure of the engine's ability to produce work and is used to accelerate. Fig. 4 shows the torque trendline of the engine speed, which shows that torsion tends to rise along with the increase in engine speed until a certain rotation and then decreases with the increase in engine speed. The increase in torque with increasing engine speed occurs because at higher speeds, the air flow entering the combustion chamber is more turbulent which will result in a mixture of air and fuel become better and the propagation of flame is also faster so that the torque value will increase. In addition, the increase in engine speed is caused by the increase in the fuel flow rate, so that as more fuel enters the combustion chamber, the torque produced will increase. But increasing engine speed will also increase friction, increase operational temperature, and increase incomplete combustion. Therefore, at a higher speed, torque will tend to decrease again.

In natural combustion air condition, that is with lambda 0.68 produces maximum torque of $15 \mathrm{Nm}$ at 6000 $\mathrm{rpm}$ engine speed. Addition of combustion air on aspirated 1 can increase maximum torque to $16.6 \mathrm{Nm}$ or increase by $10.67 \%$. Whereas the addition of air on aspirated 2 relatively did not produce significant changes compared to aspirated 1, but the addition of aspirated air 3 showed a decreasing trend compared to aspirated 1 . This was because the aspirated 3 mixture of air and fuel was poor,

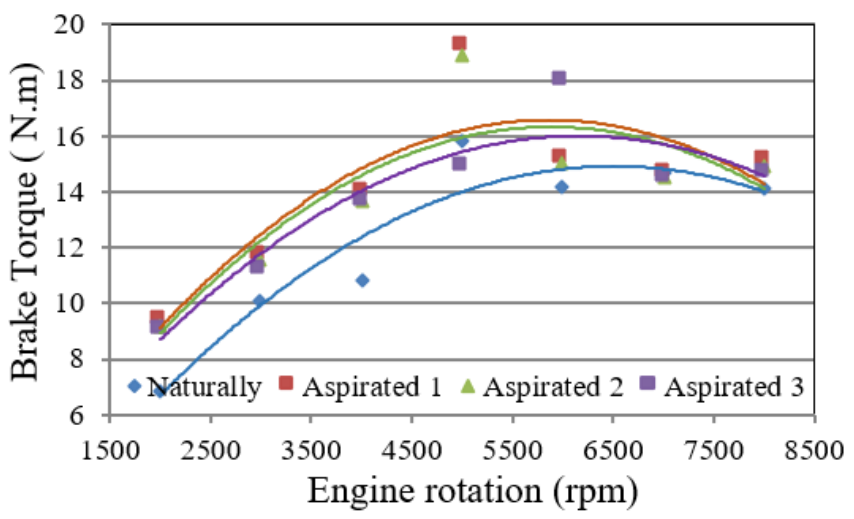

Figure 4. Torque function of engine rotation

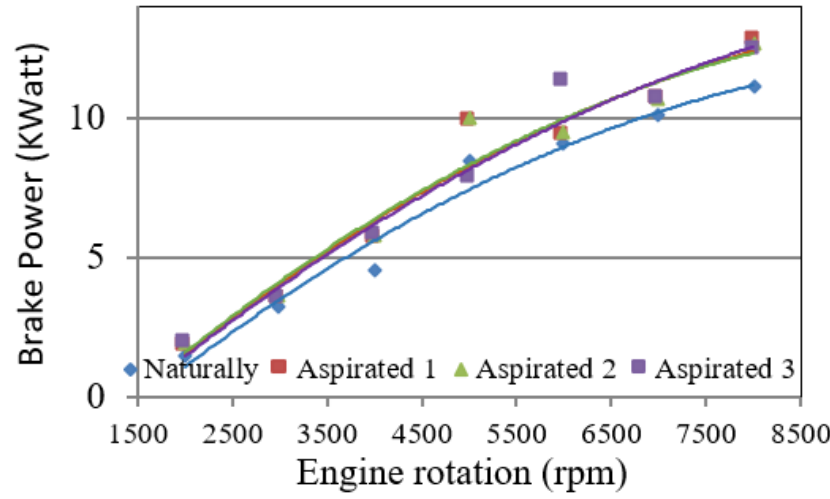

Figure 5. Power function of engine rotation

ie with lambda of 1,14 . There are 3 types of power in the internal combustion engine, namely indicative horse power (IHP), brake horse power (BHP), and friction horse power (FHP). At low speed, the power is relatively low and will be higher when the engine speed is increased. Theoretically, when the engine speed increases, the engine power will also increase because the power is the multiplication between the torque and the shaft rotation.

Fig. 5 shows the engine power trendline in each round. The power generated from the engine all increases with increasing engine speed from 2000 to $8000 \mathrm{rpm}$. In natural combustion air condition, the maximum power produced is $11.07 \mathrm{KW}$ at $8000 \mathrm{rpm}$, while the addition of supercharger with 8 volt drive motor (aspirated 1) has increased to $12.71 \mathrm{~kW}$ or an increase of $14.81 \%$. This is because the addition of air contributes to perfecting the combustion process so that the release of combustion heat is greater so that the power produced also increases. While the addition of combustion air on aspirated 2 and 3 relatively does not provide a significant increase in power.

Fig. 6 shows the trendline of the brake mean effective pressure for each engine rotation. BMEP generated from the engine tends to increase with increasing engine speed from 2000 to the highest value of $6000 \mathrm{rpm}$, and will decrease at $6000 \mathrm{rpm}$ and above. This can be explained that the pressure in the combustion chamber inc-

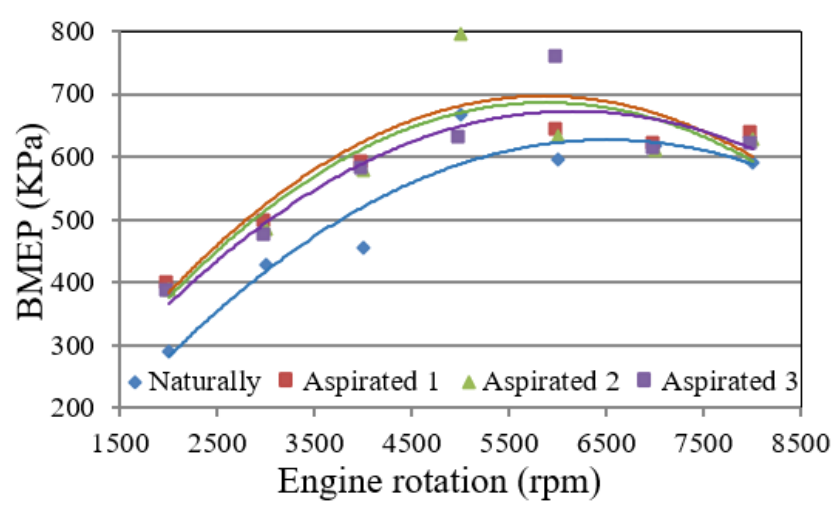

Figure 6. BMEP function of engine rotation 


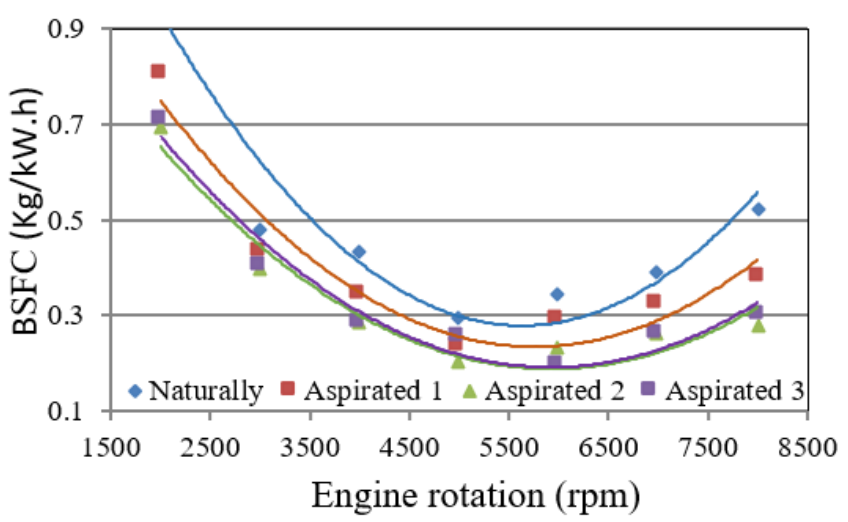

Figure 7. BSFC function of engine rotation

reases with the increase in the amount of combustion that occurs. However, after reaching a certain peak point it will decrease, because the explosion produced by combustion is not only useful to produce power, but also used to overcome the losses that occur.

In natural combustion air condition, the maximum load that can be produced is $630 \mathrm{KPa}$ at $6000 \mathrm{rpm}$, while in aspirated $1 \mathrm{BMEP}$ the maximum reaches $700 \mathrm{kPa}$ at $6000 \mathrm{rpm}$ or an increase of $11.11 \%$. Whereas in aspirated 2 , the relative value of BMEP is close to aspirated 1, while for the maximum condition aspirated 3 has decreased. This is because with increasing combustion air the mixture in the combustion chamber becomes poor, so the release of combustion heat is also reduced.

Specific fuel consumption can be defined as the fuel flow rate to obtain effective power. The specific fuel consumption value depends on the mixture of air and fuel burning in the combustion chamber. With the more perfect combustion, the smaller the resulting fuel. Fig.7 shows the trend of specific fuel consumption at each engine rotation with variations in combustion air intake. In natural air intake conditions, the minimum BSFC is $0,29 \mathrm{~kg} / \mathrm{kW}-\mathrm{h}$, while in aspirated conditions 1 , the minimum BSFC is reduced to $0.24 \mathrm{~kg} / \mathrm{kW}-\mathrm{h}$ and on aspirated 2, BSFC decreases again to 0,19 , while on aspirated 3 the BSFC value is close to aspirated 2. In general, the specific fuel consumption from low rpm to high will experience a decrease to a certain engine speed and then will increase again. This is caused by the higher flow turbulence along with the increase in engine speed, so that the homogeneity of the mixture of fuel and air is better and produces a more perfect combustion.

The value of thermal efficiency depends on the mixture of air and fuel burning in the combustion chamber, Fig. 8 shows the trendline of thermal efficiency of the engine at each engine speed. In conditions of natural combustion air intake, the maximum thermal efficiency produced is $45.2 \%$ at $5500 \mathrm{rpm}$. While the addition of combustion air on aspirated 1 increased to $55.8 \%$, and on aspirated 2 increased to $67 \%$, while the addition of aspirated 3 results close to aspirated 2 . This can be explained that the addition of air to a certain value (lambda $0.8 \mathrm{~s} /$

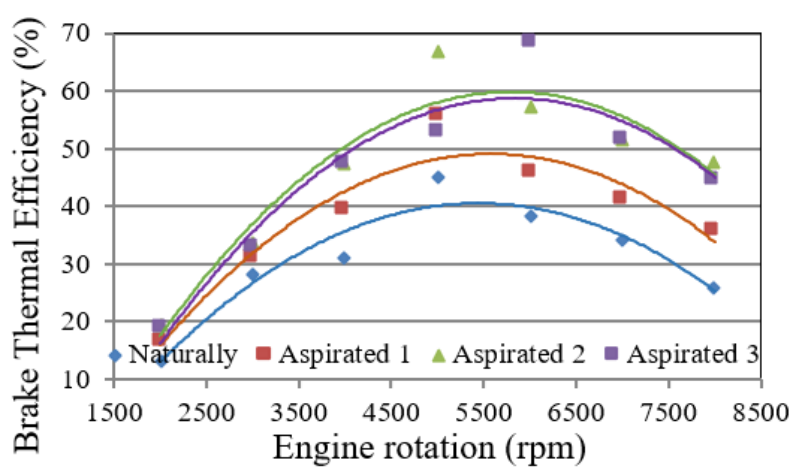

Figure 8. Thermal eff. function of engine rotation

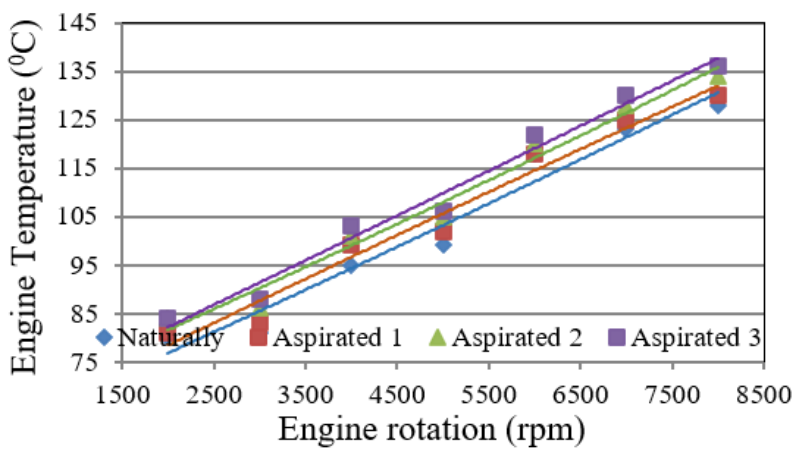

Figure 9. Engine temperature function of engine rotation

d 1,1 ) tends to improve the combustion process so that it can increase thermal efficiency. But the addition of higher combustion air actually reduces the combustion heat produced, because it does not contribute to the oxidation process.

Fig. 9 shows the cylinder temperature graph of the engine rotation function block. The results show that the block cylinder temperature tends to increase with increasing engine speed. This is due to the high rotation, the higher the amount of fuel entered and the friction between the piston and the cylinder wall, the greater the cylinder block temperature increases. Under conditions of inclusion of natural combustion air, the block cylinder temperature occurs at $128^{\circ} \mathrm{C}$. While the addition of combustion air on aspirated 1, 2 and 3 shows the tendency of the cylinder block engine temperature to rise to be $130^{\circ} \mathrm{C}$, $134^{\circ} \mathrm{C}$ and $136^{\circ} \mathrm{C}$ respectively.

As shown exhaust emissions shown are carbon monoxide (CO) and hydro carbon (HC) emissions. Carbon monoxide is one of the exhaust gases from combustion which is harmful to health and also has a bad impact on the environment. CO emissions in motorized vehicle exhaust gases are caused by incomplete combustion in the combustion chamber. When low engine speed, the turbulence that occurs is too small to form the homogeneity of the mixture of air and fuel. This causes the mixture to become rich so that $\mathrm{CO}$ emissions are also relatively high. Along with the increase in engine speed, turbulence of the 




Figure 10. CO emissions function of engine rotation

combustion air flow is getting better, so that the mixing process is more homogeneous and more perfect combustion. This is indicated by the smaller CO. Emissions. But the increase in rotation is getting higher, causing the combustion process to be relatively short so that $\mathrm{CO}$ emissions tend to increase again.

As shown in Fig.110 in conditions of natural combustion air intake, CO emissions of at least $1.08 \%$ occur at $3500 \mathrm{rpm}$ engine speed. Addition of combustion air to aspirated 1 can reduce CO emissions to $1.04 \%$. The addition of air to aspirated 2 and 3 can reduce $\mathrm{CO}$ emissions that are close to $1 \%$. This can be explained that the addition of combustion air contributes to perfecting the oxidation process of $\mathrm{CO}$ to $\mathrm{CO} 2[9]$.

As shown in Fig. 11 HC emissions tend to decrease along increasing engine speed. After the $\mathrm{HC}$ emission is at its lowest point, which is at $5000 \mathrm{rpm}$ rotation and after that the engine rotation tends to increase $\mathrm{HC}$ emissions. In conditions of natural combustion air intake, HC emissions are at least $70 \mathrm{ppm}$, which occurs at $5000 \mathrm{rpm}$. The addition of combustion air to aspirated 1, HC emissions reduced to $58 \mathrm{ppm}$ occurs at $5500 \mathrm{rpm}$ engine speed. Addition of aspirated combustion air 2 and 3 decreases HC emissions to 53 and $52 \mathrm{ppm}$ at $6000 \mathrm{rpm}$.

Theoretically HC emissions will decrease with increasing engine speed. This is due to the increase in homogeneity of the air and fuel mixture along with the increase in engine speed. However, in high rotation, HC

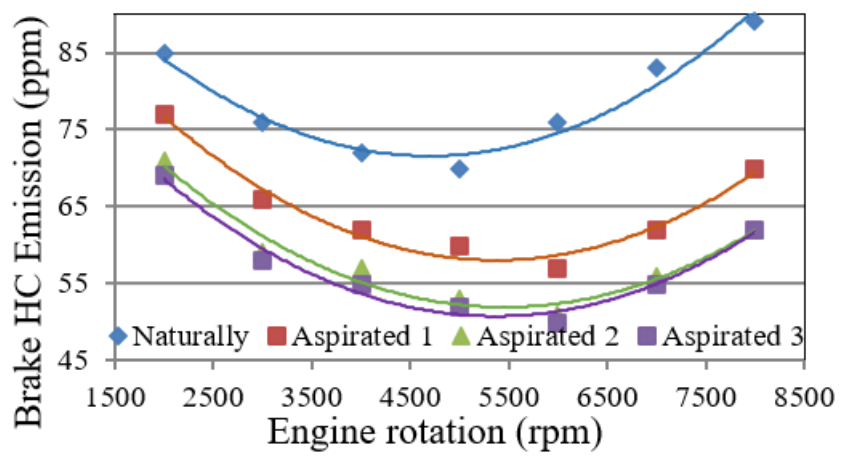

Figure 11. EHC emissions function of engine rotation emissions tend to increase, because the burning time is getting shorter so that most of the hydrocarbons have not been burned. Decrease in HC emissions is done by adding combustion air to make the fuel mixture and air more homogeneous resulting in a more perfect combustion. As a result $\mathrm{HC}$ emissions have decreased.

\section{Conclusions}

The results of this study indicate that the natural intake system in Sinjai-150-bioethanol fueled engines produces a relatively rich air fuel ratio, with an average lambda of 0.68 resulting in less optimal performance. The addition of aspirated 1 and 2 combustion air resulted in an increase in performance and emissions with the results in the form of average lambda at intervals of 0.8 to 1.1. On aspirated 1 and 2, increase in performance in the form of torque, power and electricity reached an average of 14.73. On aspirated 2, thermal efficiency increase averaged $50.32 \%$, specific fuel consumption decrease averaged $32.74 \%$, and CO and HC emissions reduction average of $7.43 \%$ and $25.77 \%$.

\section{References}

[1] A. Sugiyono, L. M. Anindhita, A. Wahid, and Adiarso, "Indonesia energy outlook 2016: Energy development in supporting green industry," Jakarta: BPPT, p. 21, 2016.

[2] B. Sudarmanta, S. Darsopuspito, and D. Sungkono, "Influence of bioethanol-gasoline blended fuel on performance and emissions characteristics from port injection sinjai engine $650 \mathrm{cc}$," in Applied Mechanics and Materials, vol. 493, pp. 273-280, Trans Tech Publ, 2014.

[3] N. Jeuland, X. Montagne, and X. Gautrot, "Potentiality of ethanol as a fuel for dedicated engine," Oil \& Gas Science and Technology, vol. 59, no. 6, pp. 559-570, 2004.

[4] M. E. Paloboran, I. N. Sutantra, B. Sudarmanta, M. Paloboran, I. Sutantra, and B. Sudarmanta, "Performances and emissions characteristics of three main types composition of gasoline-ethanol blended in spark ignition engines," Int. Rev. Mech. Eng, vol. 10, no. 7, p. 552, 2016.

[5] B. Sudarmanta, D. Prayoga, A. Wikarta, and I. N. Sutantra, "Cold start technology for dedicated bioethanol sinjai-150 engine," in AIP Conference Proceedings, vol. 1983, p. 020036, AIP Publishing, 2018.

[6] R. C. Costa and J. R. Sodré, "Compression ratio effects on an ethanol/gasoline fuelled engine performance," Applied Thermal Engineering, vol. 31, no. 2-3, pp. 278283, 2011.

[7] B. Sudarmanta, B. Junipitoyo, A. B. K. Putra, and I. N. Sutantra, "Influence of the compression ratio and ignition timing on sinjai engine performance with 
50\% bioethanol-gasoline blended fuel," ARPN Journal of Engineering and Applied Sciences, vol. 11, no. 4, pp. 2768-2774, 2016.

[8] S. I. S. B. D. G. Paloboran, M., "A strategy in adjustment of combustion parameters of sipfi engine with pure bioethanol fuelled for a high performance and low emission," WSEAS Transaction Environment and Development Journal, vol. 13, pp. 421-430, Nov. 2017.

[9] G. Najafi, B. Ghobadian, T. Tavakoli, D. Buttsworth, T. Yusaf, and M. Faizollahnejad, "Performance and exhaust emissions of a gasoline engine with ethanol blended gasoline fuels using artificial neural network," Applied Energy, vol. 86, no. 5, pp. 630-639, 2009. 